\title{
Dynamics of lake area on the Qinghai-Tibet plateau from 2000 to 2015
}

\author{
Xianghong Che ${ }^{\mathrm{a},}{ }^{*}$, Min Feng $^{\mathrm{b}}$, Jiping Liu ${ }^{\mathrm{a}}$, Yong Wang ${ }^{\mathrm{a}}$, Qing Sun ${ }^{\mathrm{c}}$ \\ ${ }^{a}$ Research Center of Government Geographic Information System, Chinese Academy of Surveying \& Mapping, Beijing 100830, \\ China, chexh.15b@gmail.com \\ ${ }^{b}$ Global Land Cover Facility, Department of Geographical Sciences, University of Maryland, College Park, MD 20742, USA, \\ fengm@umd.edu \\ ${ }^{c}$ Collaborative Innovation Center on Forecast and Evaluation of Meteorological Disasters (CIC-FEMD), Nanjing University of \\ Information Science \& Technology, Nanjing 210044, China, sunqingmeteo@gmail.com \\ * Corresponding author
}

\begin{abstract}
The distribution of lakes in space and its change over time are closely related to many environmental and ecological issues, and are important factors that must be considered in human socio-economic development. In this paper, the water detection method is utilized to derive monthly water bodies, and then a seed set expansion approach was explored to extract lakes larger than $0.1 \mathrm{~km}^{2}$. Since lakes number and size can effectively reflect the distribution characteristics of water bodies, their change of the number, area and distribution are analyzed. The results shows there is a prominent power exponent relation between lake size and lake number for the Qinghai-Tibet plateau (QTP), which is similar to existing analysis of global scale. The number density of medium size of lakes on the QTP is higher than other types of lakes. The number of lakes displayed a decreasing trend from 2000 to 2015 with the $\mathrm{R}^{2}$ of 0.41 . There was an increasing trend with an increasing rate of $356.86 \mathrm{~km}^{2} /$ year $(0.72 \%)$. Specifically, $46.54 \%$ of lakes area are increasing, and mostly distributed in Alpine grassland and shrub woodlands zone of the central Tibetan plateau. Shrinking lakes mostly with the area less than $10 \mathrm{~km}^{2}$ are situated on the woodland and shrub and grass areas in south-eastern Tibet. Finally, the analysis of monthly lake area of four lakes at the source of the Yellow River demonstrates the lakes area of each month from June to September witness an increasing trend, and the largest increasing rate is on June, which has a strong seasonality.
\end{abstract}

Keywords: water detection, QTP, lakes dynamics, Landsat, lake areas

\section{Introduction}

Lakes, as essential components of the hydrological and biogeochemical water cycles, influence many aspects of ecology, economy, and human welfare (Liu et al,, 2009, Wang et al., 1998). In the past several decades, dramatic ecological, morphological, and areal changes of water bodies have occurred in many lakes in the world (Feng et al., 2012). It is critical to understand the spatial-temporal patterns of areal changes as its changes can lead to flooding or drought, and water shortages, thus imposing significant consequences to human life, agricultural systems, global water, and food security (Feyisa et al., 2014, Hanjra et al., 2010).

Qinghai-Tibet plateau is the world's highest and largest plateau which is surrounded by massive mountain ranges. There are plenty of lakes and glaciers covering this area, and the variation of lake area is closely related to the regional and global climate changes. Due to the QinghaiTibet plateau 's remoteness, high altitude, thin atmosphere, and harsh weather conditions, the quantitative lake water extents and their changes are still poorly known. Using satellite remote sensing, there have been numerous studies related to dramatic areal changes of lakes on different spatial-temporal resolutions. However, the water dynamics analysis at monthly or higher temporal resolution tend to using MODIS images of $500 \mathrm{~m}$ and $1 \mathrm{~km}$ resolution, which makes it incapable to precisely analyze the dynamics for small bodies. For example, Sun et al. mapped water surface changes over 629 lakes in China using 8-day MODIS images (500m) (Sun et al., 2014). Che et al. quantified lake area in each month in Qinghai-Tibet plateau for 14 years and analyzed the change of lake area at both monthly and annually scales using MODIS observations (Che et al., 2015). Klein et al. derived inland water bodies extents for the months April, July and September from 1986 till 2012 for the region of Central Asia (Klein et al., 2014). The analysis of lake dynamics for Central-Asia area at higher resolution such as $30 \mathrm{~m}$ resolution or even better, primarily focused on one or multiple typical lakes (Aral Sea, Siling Co, Nam-co, Ulan ul et al) over the inconsecutive period, leading to some pseudo change (Bai et al., 2011, Chen et al., 2015, Wu et al., 2009, Yan et al., 2014). Therefore, it is rare for lakes dynamics at high spatial and temporal resolution for Qinghai-Tibet plateau, which is the objective of this study analyzing monthly pattern of lakes dynamics for this area at $30 \mathrm{~m}$ spatial resolution. 


\section{Study area and data source}

\subsection{Study area}

The study area in this research is called as Qinghai-Tibet plateau (QTP) consisting Xizang and Qinghai province (Figure 1). The QTP has an average elevation of more than $4000 \mathrm{~m}$ and is now called "the Third Pole" of the Earth and the "Asian water tower", which is covered by plenty of lakes and glaciers surrounded by massive mountain ranges surrounded by massive mountain ranges (Lu et al., 2005). Thus QTP provides fresh water resources for over 1 billion people through feeding the river systems (Barnett et al., 2005). However, due to global warming, QTP has undergone dramatic changes such as accelerating glaciers melt, permafrost degradation and increasing temperature extremes, which leads to abrupt expansion or shrinkage of lakes area (Zhang et al., 2011). It is critical to precisely analyze the change pattern of lakes to prevent flooding and drought, thus reasonably utilizing the water resources.

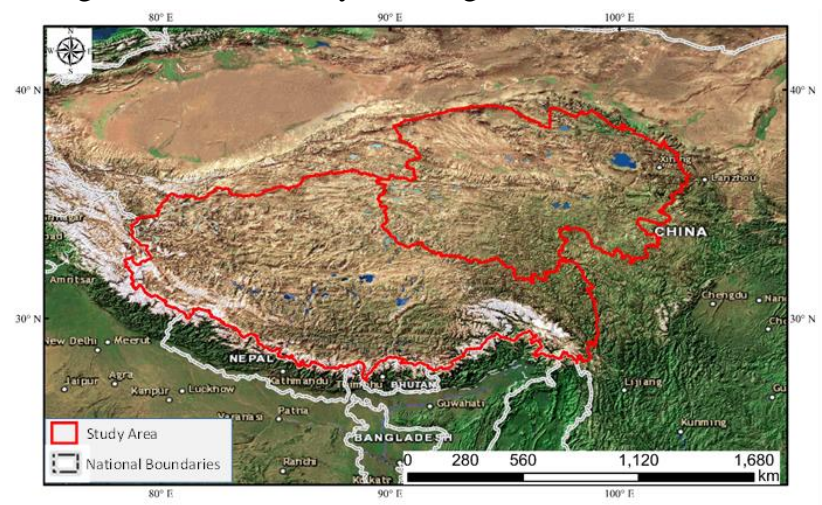

Figure 1. The location of Qinghai-Tibet plateau

\subsection{Data source}

All available Level 1 Terrain (corrected) (L1T) Landsat 5 Thematic Mapper (TM), Landsat 7 Enhanced Thematic Mapper-plus (ETM+) and Landsat 8 Operational Land Imager (OLI) images with more than 20\% clear observations acquired from 2000 to 2016 was used, which is covered by 116 Landsat world reference system-2 path/row combinations. The number of Landsat scenes across study area varied between 261 and 449 with an average of 22 images per year per path/row, with fewer images $(\sim 16)$ in the western part of the study area (Figure 2). Landsat 5, 7 and 8 with near-polar orbit observes Earth every 16 days, thus leading to two satellites operate concurrently with an 8-day cycle. In addition, owing to adjacent orbits overlaps from $7.3 \%$ at the Equator to $68.3 \%$ at $70^{\circ}$ latitude, the observation within side-lap pixels doubles (Pekel et al., 2016), which greatly improve the temporal resolution of images.

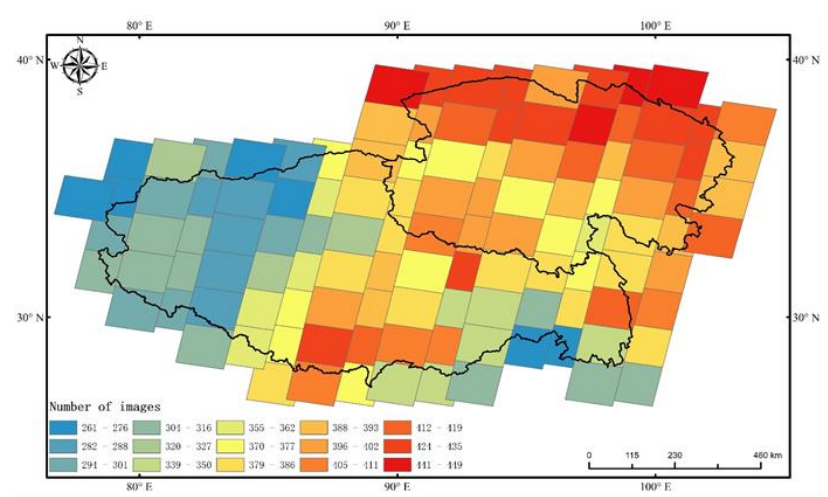

Figure 2. Total number of Landsat observations on the QTP

\section{Methodology}

\subsection{Water detection}

Monthly water extents are derived from a classificationtree model (C5.0) and temporal interpolation. The Incorporated spectral indices, MODIS water data and topographic data, the C5.0 decision tree is built to extract water separately on each scene of Landsat images with hierarchical weighted sampling space. Subsequently, based on multiple observations and acquisition times on pixel scale, monthly water extents are derived by time series interpolation. A complete exploration of Monthly water extents derivation is beyond the scope of this article, but more details can be found in (Che et al., 2018).

\subsection{Lakes identification}

A seed set expansion approach is explored to derive lake extent and its unique label, which is required to analyze time-series areal change of each lake. The approach used HydroLAKES database as seed set. The HydroLAKES database was created by compiling, correcting, and unifying several near-global and regional datasets (Messager et al., 2016). The resulting map scale is estimated to be between 1:100,000 and 1:250,000 for most lakes globally, with some coarser ones at 1:1 million, which includes the lakes with surface area more than $0.1 \mathrm{~km} 2$. Lake polygons were rasterized in according to the unique ID of each lake. The seed set is able to provide the location of each lake, thus facilitating the decrease of misclassified water. In addition, some lakes are observed on several adjacent images, so the seed set guarantee that the image-crossed water bodies are labelled to one lake. The seed set expansion process is as followed:

(1) The polygons of seed dataset were aggregated to the projection of monthly water result and then rasterized to pixel footprints of $90 \mathrm{~m}$ resolution of water extent for comparison to minimize the error caused by re-projection and data format.

(2) The pixels belonging to the same lake were identified and labelled, which were regarded as initial lake pixel sets.

(3) There likely to be some separated water bodies for one lake, and because of water dynamics, some lakes probably merge or separate. In order to guarantee a unique ID for these lakes, these parts or merged lakes were assigned an ID from the lakes with larger water area. Therefore, the 
pixel set of each lake is sorted, and the expansion started from the pixel set of largest lakes.

(4) The pixel was popped from initial lake pixels set of one lake in sequence. This pixel was labelled as the lake pixel and given a traversal state if the pixel is classified as water and in un-traversal state. In the meantime, the un-traversal pixels within $3 \times 3$ moving window centered on this labelled pixel were pushed into the initial lake pixels set.

(5) The step (4) was repeated until there were no water pixels in initial lake pixels set. The lake extent was comprised of all the labelled pixels.

(6) By repeating step (4-5) with its initial water pixels for each lake, the extent of all lakes were determined.

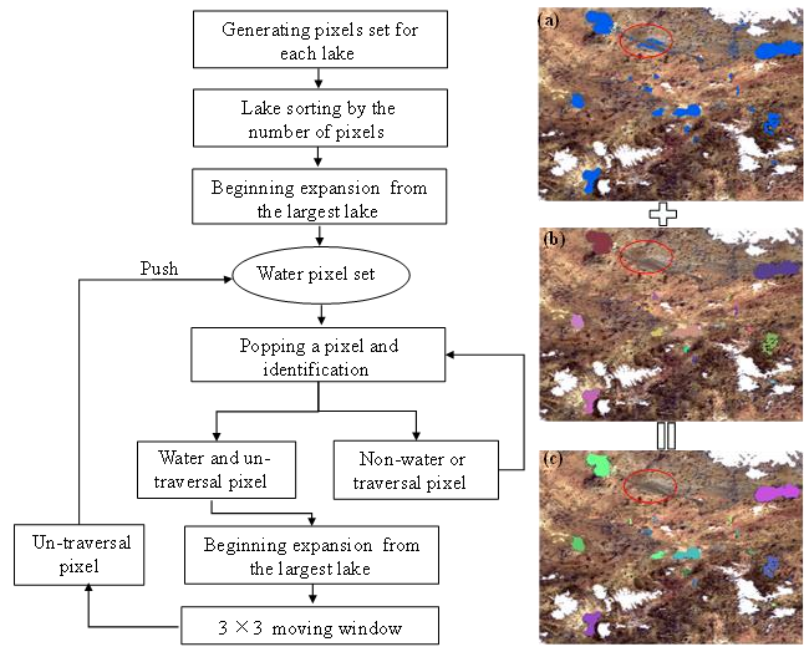

Figure 3. The flow chart of seed set expansion algorithm and test result ((a) monthly water extent; (b) seed set of lakes; (c) expanded lakes)

\subsection{Change analysis}

Considering the lower accuracy of water detection in colder months (Che et al., 1987), the change analysis of lakes over Central Asia area were made for four months from June to September from 2000 to 2015. The approach to change analysis was predicated on using a linear trend (Ordinary Least Square, OLS) to smooth the monthly and annual time series of data when determining areal and numeral change of lakes ( $\mathrm{Li}, 1989)$. It is called Change Speed (Cs) with the unit of $\mathrm{km}^{2}$ per year or per month. We further imposed the objective constraint of statistical significance of the trend to define change of lakes using the T-test model (Baldi et al., 2001). If the T-test was not statistically significant $(\mathrm{p} \geqslant 0.05)$, we defined there was not a linear trend of lake change and vice versa. To make different size of lakes comparable, Change Velocity $(\mathrm{Cv})$ was calculated with CS divided by the mean area of the lake from 2000 to 2015 .

\section{Results}

\subsection{Change of the number of lakes}

The number of lakes on QTP displayed a decreasing trend from 2000 to 2015 with the $\mathrm{R}^{2}$ of 0.41 . The biggest number of lakes accounted for 2835 in 2000 , and declined to the lowest value of 2713 in 2010. The number of lakes reduced by nearly 4 per year (Figure 4 ).

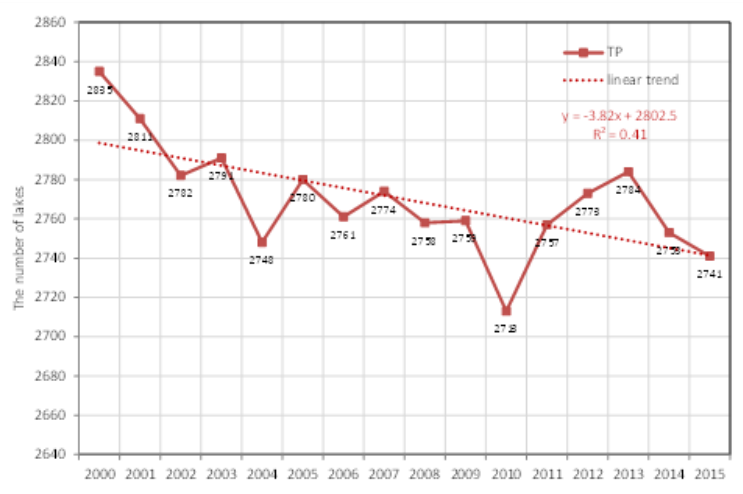

Figure 4. The change trend of the number of lakes on the QTP The pie chart in Figure 5 showed there were the largest proportion of lakes with surface area less than $1 \mathrm{~km}^{2}$, which accounted for $62.24 \%$. The percentage of the number of lakes decreased with the area of lakes to $0.13 \%$ for that of larger than $1000 \mathrm{~km}^{2}$. In addition, it is found the number of lakes and its size had a power exponential relation, which is similar to the global distribution of lakes. The lakes were categorized into 8 types according to their sizes ([0.01, 0.05], [0.05, 0.1], [0.1, 0.5], [0.5, 1.0], [1.0, 10.0], $[10,100],[100,1000],[1000,-])$. We divided the number of lakes distributed each interval by the area of the QTP to derive the density of lakes. This normalization indicated the number of lakes per the area of $100 \mathrm{~km}^{2}$. The curve graph in Figure 5 showed the quantitative relation between the number of lakes and its size. The exponent signs of the number of lakes change was -0.55 , and lesser than that of global distribution (-0.9926) (Lehner et al., 2004), which demonstrated a smaller reducing speed of the number of lakes with the increase of lake size. The number density of larger lakes was small, and the lakes with medium size dominated on QTP.
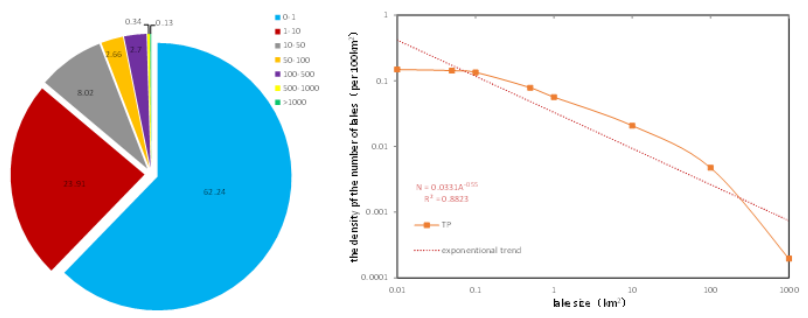

Figure 5. The distribution trend of the number for different sizes on the QTP

\subsection{Change of the area of lakes}

From 2000 to 2015, there was a significant linear increasing trend for the total area of lakes on the QTP with the $\mathrm{R}^{2}$ of 0.825 (Figure 6). There was stable increase from $45869.91 \mathrm{~km}^{2}$ to $45896.49 \mathrm{~km}^{2}$ for the period between 2000 and 2013 except a sudden reduction on 2010. Since 2013, a gradual decrease happened, and the reduced area was $4542.3 \mathrm{~km}^{2}$ (Cs: $356.86 \mathrm{~km}^{2} /$ year and $\mathrm{Cv}: 0.72 \%$ ). In addition, the fluctuation from June and September of each year was calculated with annual standard deviation coefficient, also called as variation coefficient. The QTP experienced a decreasing trend of fluctuation, especially 
without significant fluctuation during warm months since 2011.

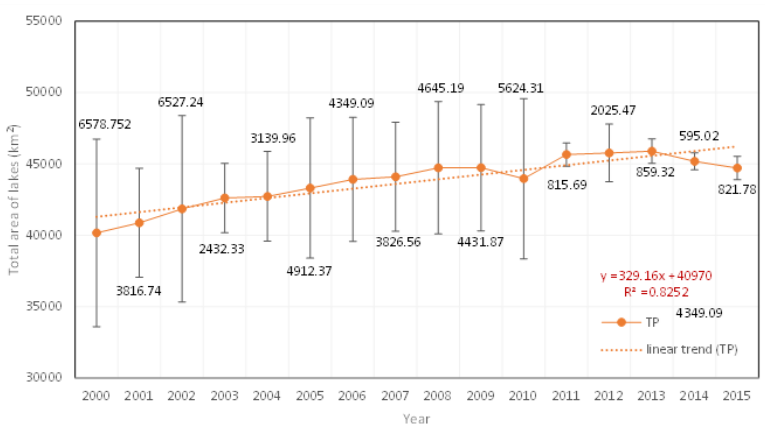

Figure 6. The change trend and annual fluctuation of the total lakes area on the QTP

The area change of lakes of different sizes was outlined in Table 2. The small and medium area of lakes had a decrease while large lakes with the area larger than $100 \mathrm{~km}^{2}$ showed an opposite trend. It is apparent that there was a shift from small and medium lakes to the large ones. Specifically, there was a decreasing trend for the lakes with the area ranged from $1 \mathrm{~km}^{2}$ to $10 \mathrm{~km}^{2}$ and from $10 \mathrm{~km}^{2}$ to $50 \mathrm{~km}^{2}$, where the Cs stood at $11.19 \mathrm{~km}^{2}$ and $18.24 \mathrm{~km}^{2}$ respectively. The area of lakes $\left(0 \mathrm{~km}^{2} \sim 1 \mathrm{~km}^{2}\right.$ and 50 $\mathrm{km}^{2} \sim 100 \mathrm{~km}^{2}$ ) were stable during 16 years. Conversely, lakes larger than $1000 \mathrm{~km}^{2}$ showed the most significant rising with the $\mathrm{R}^{2}$ of 0.93 .

Table 1 . The yearly change of lakes of different sizes

\begin{tabular}{cc|c|c|c}
\hline Lake types(km2) & Area proportion $(\%)$ & $\mathrm{Cv}\left(\mathrm{km}^{2} /\right.$ year $)$ & $\mathrm{Cs}(\%)$ & $\mathrm{R}^{2}$ \\
\hline $0 \sim 1$ & 1.12 & 0.54 & 0.10 & 0.08 \\
$1 \sim 10$ & 4.32 & -11.19 & -0.52 & $0.51^{*}$ \\
$10 \sim 50$ & 10.37 & -18.24 & -0.35 & $0.64 *$ \\
$50 \sim 100$ & 10.37 & -0.85 & -0.02 & 0.02 \\
$100 \sim 500$ & 31.05 & 171.92 & 1.11 & $0.88^{*}$ \\
$500 \sim 1000$ & 12.18 & 42.87 & 0.71 & $0.52^{*}$ \\
$>1000$ & 18.39 & 128.935 & 1.41 & $0.93 *$ \\
\hline
\end{tabular}

Note: * means statistically significant

\subsection{Spatial-temporal change of lakes area}

The statistical significance of change for lakes were first tested, which showed the statistical significance of lakes decreased with the area reduced, and the testing results provided good performance for change analysis of lakes. Specifically, linear change trend was statistically significant $(p \geqslant 0.05)$ for $68 \%$ of lakes with the area larger than $50 \mathrm{~km} 2$ on the QTP. There was $84 \%$ for the lakes larger than $100 \mathrm{~km}^{2}$ with significant linear trend. It is also statistically significant for all of lakes with the area larger than $1000 \mathrm{~km}^{2} .61 \%$ of lakes fluctuating from $10 \mathrm{~km}^{2}$ to $50 \mathrm{~km}^{2}$ saw a linear change, but there was not such a change for lakes smaller than $10 \mathrm{~km}^{2}$.

There was $53.46 \%$ of shrinking lakes, and the majority of these lakes were small $\left(<10 \mathrm{~km}^{2}\right)$ and changed with the $\mathrm{Cv}$ from $-10 \%$ to $-1 \%$, which concentrated on forests, shrubs and meadows regions of southeastern Tibet. The expanding lakes mostly were on the alpine grassland of central TP and alpine desert of North Tibetan plateauKunlun Mountain. The $\mathrm{Cv}$ of these lakes fluctuated from $1 \%$ to $10 \%$.

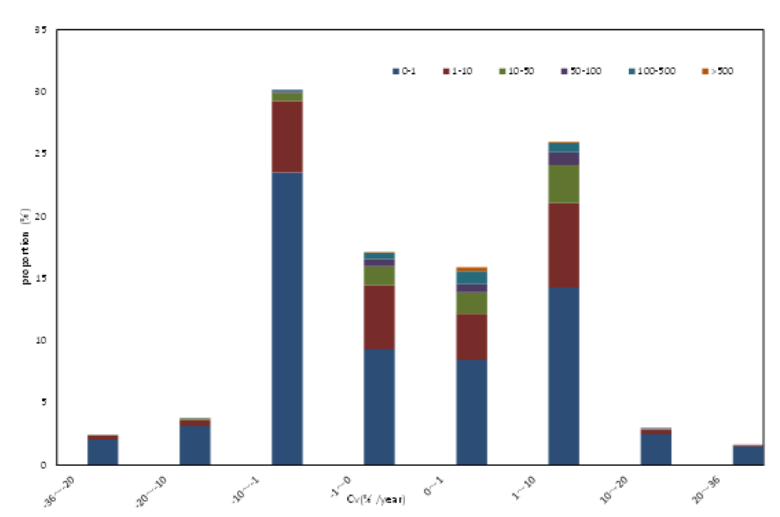

Figure 8. Lakes percentage of different change velocity on the QTP

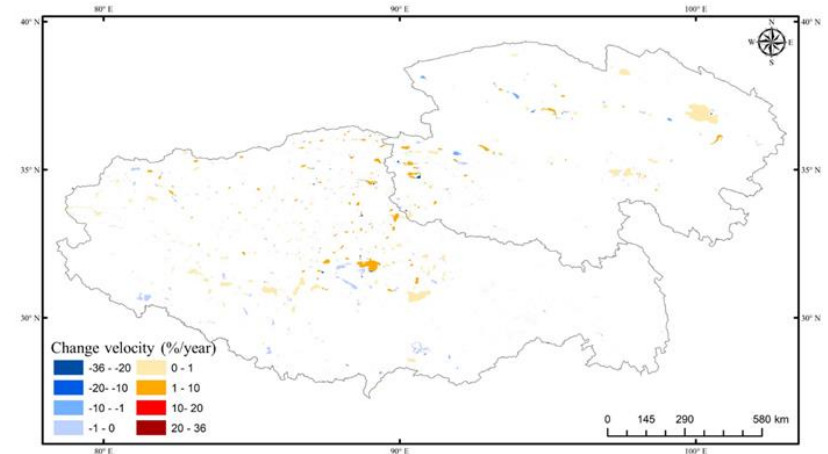

Figure 9. The spatial distribution of yearly change for the QTP

\section{Discussions}

The source of the Yellow River on the QTP has large historical extent variation and make easy comparison to existing analysis, thus selecting four lakes in this region to analyze the yearly and monthly change. As the largest water conservation area at the source of the Yellow River, Longre Co (lake I , N34 ${ }^{\circ} 52^{\prime}$, E98 ${ }^{\circ} 55^{\prime}$ ), Ayonggongma Co (lake II, N34 ${ }^{\circ} 49^{\prime}$, E98 ${ }^{\circ} 06^{\prime}$ ), Ayonggama Co (lake III, N34 ${ }^{\circ} 47^{\prime}$, E98 ${ }^{\circ} 12^{\prime}$ ), and Ayongwama Co (lake IV, N34 $46^{\prime}$, E98 ${ }^{\circ} 17^{\prime}$ ) are located in the center of Madoi County of Qinghai province. They are supplied by rivers in the south and precipitation. Average annual temperature in the lakes catchment is $-4.1^{\circ} \mathrm{C}$, and the annual precipitation is around $303.9 \mathrm{~mm}$. Anthropogenic activity and climate change had led to many influences such as water level drop, grassland desertification and water resource conservation decline et al. Flooding and drought events have been recorded in Madoi County (Disaster Reduction, 2007).

Most of Lake II and III had stable water body while the whole lake I and the north part of lake IV showed high volatility (Figure 10). Four lakes saw an annually decrease until 2004, and a subsequent increase by 2015 . The area decrease was consistent with devastated ecological environment of the source area of the Yellow River since the 1970s (land desertification, meadow degradation). However, the area increase since 2004 primarily benefited from grassland return and ecological protection project implemented in 2003 (Wu et al., 2008). 


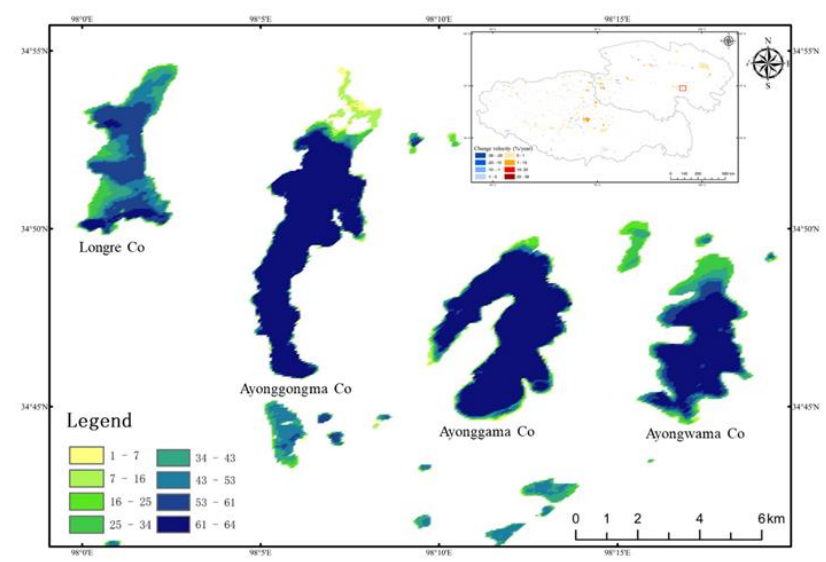

Figure 10. The area change of four lakes of yellow river source region from 2000 to 2015

There was the most significant increasing trend for Lake I with the $\mathrm{R}^{2}$ of 0.84 , which was followed by Lake IV (0.52). Lake II and III were stable and had no apparent inter-annual change feature. The maximum area of Lake I was $18.778 \mathrm{~km}^{2}$ in 2010 , and the minimum area was 3.418 $\mathrm{km}^{2}$ in 2003. The increase rate was $1.15 \mathrm{~km}^{2} /$ year. Apparently, the fluctuation within the year were dramatic, especially a nearly dry state from January to May in 2007 showed in Figure 12, which was likely to be related to the exploitation and utilization of salt deposits during this period ( $\mathrm{Lu}$ et al., 2005). It is found from Figure 11 the change trend of lake area on MODIS scale were similar to that of Landsat scale, but it had an obvious underestimation for four lakes. Lake II fluctuated between the minimum area of $26.228 \mathrm{~km} 2$ in 2005 and $31.31 \mathrm{~km} 2$ in 2011 without obvious linear change while the analysis for MODIS result showed an obvious linear change. Lake III also had no change trend with the average area of $28.023 \mathrm{~km}^{2}$. Lake IV changed linearly with the increasing rate of $0.55 \mathrm{~km}^{2} /$ year. Although the details related to water dynamics was detected on Landsat and MODIS results, there was still an area underestimation.
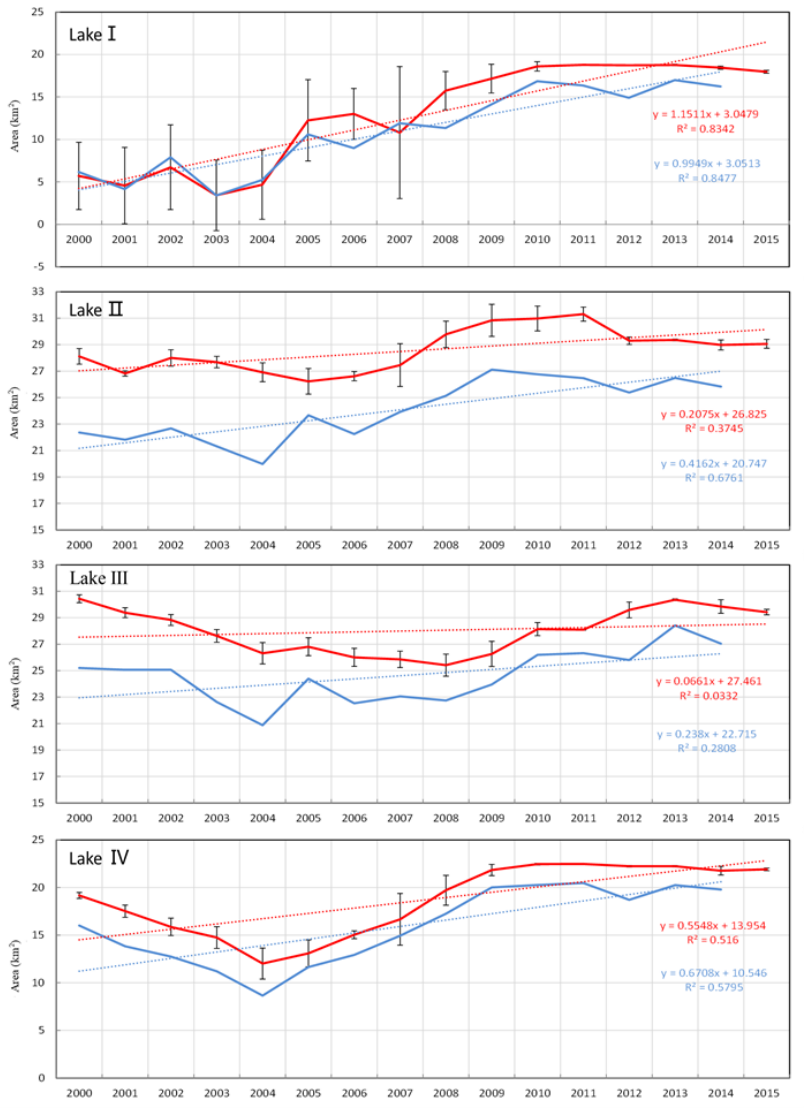

Figure 11. The yearly change trend of four lakes (red solid line: lake area; red dashed line: linear trend; error bar: annual standard deviation; blue solid line: lake area at $250 \mathrm{~m}$ resolution (Che et al, 2017); blue dashed line: corresponding linear trend)

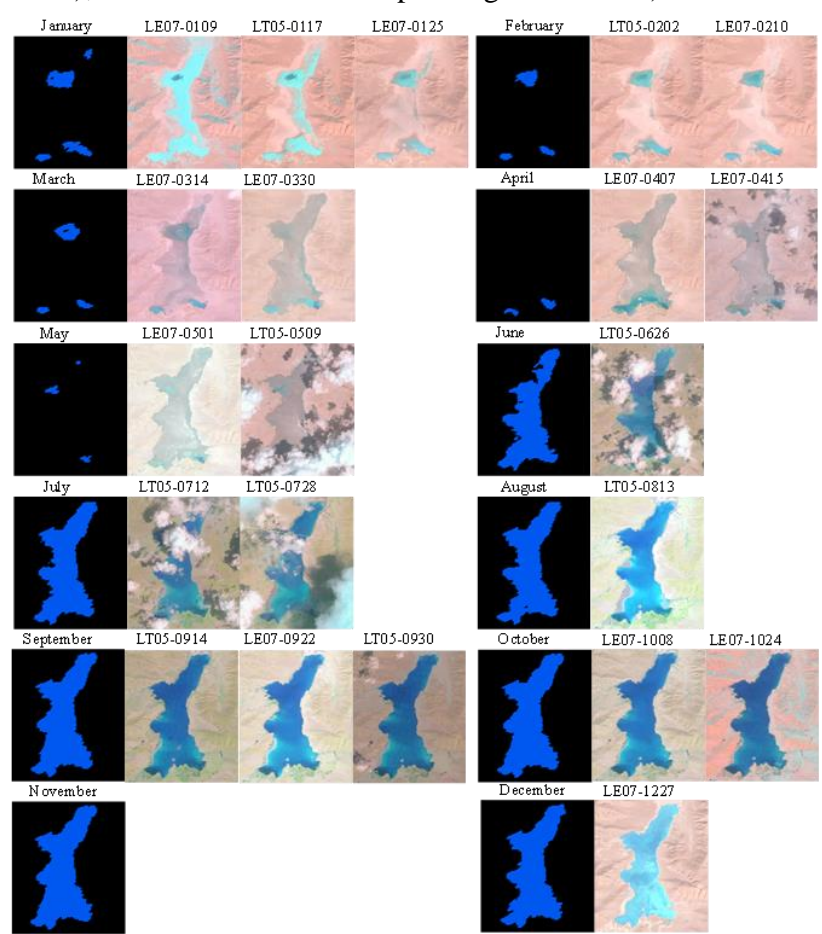

Figure 12. The water extent and Landsat images of Lonere CO on 2007

Figure 13 showed the monthly water surface area fluctuation from 2000 to 2015 . The water surface of LakeIincreased significantly from June to September, 
while there was no significant monthly difference for the other three lakes. Lake I, II and IV experienced an increasing trend from June to September except Lake III. LakeIhad the most obvious increasing trend, especially in June, which was followed by Lake IV and Lake II. However, there was no obvious monthly change for Lake III. Even though four lakes are in the same basin, the yearly and monthly changes were different, which probably was related to the shallow lake basin and small water surface (Sun et al., 2014).
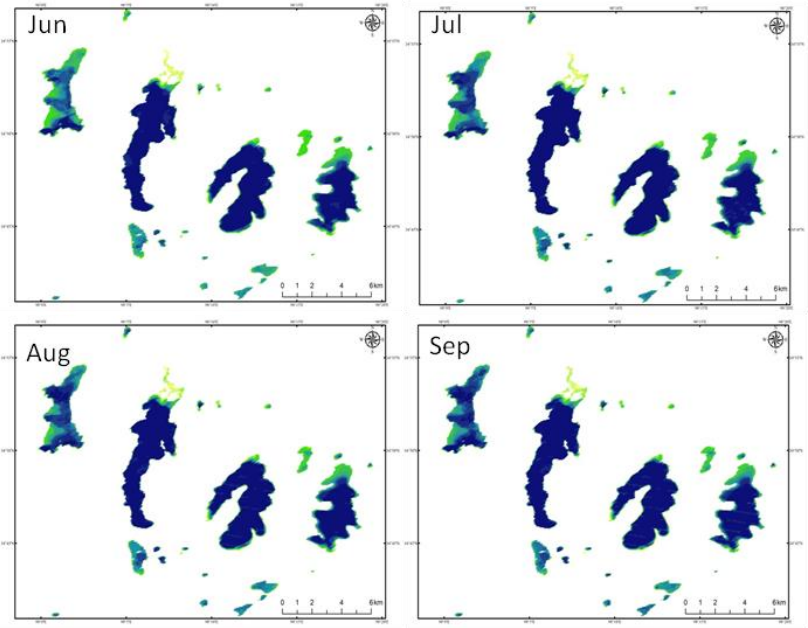

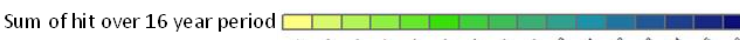

Figure 13. The monthly extent change of four lakes

Table 2. The monthly change statistics of four lakes

\begin{tabular}{c|cc|cc|cc|cc}
\hline & \multicolumn{2}{|c|}{ Lake I } & \multicolumn{2}{c|}{ Lake II } & \multicolumn{2}{c|}{ Lake III } & \multicolumn{2}{c}{ Lake IV } \\
& Slope & $\mathrm{R}^{2}$ & slope & $\mathrm{R}^{2}$ & slope & $\mathrm{R}^{2}$ & slope & $\mathrm{R}^{2}$ \\
\hline Jun & 1.04 & $0.82^{*}$ & 0.21 & $0.36^{*}$ & 0.05 & 0.01 & 0.49 & $0.47^{*}$ \\
Jul & 0.93 & $0.71^{*}$ & 0.19 & $0.34^{*}$ & 0.07 & 0.03 & 0.51 & $0.53^{*}$ \\
Aug & 0.71 & $0.53^{*}$ & 0.19 & $0.31^{*}$ & 0.07 & 0.03 & 0.50 & $0.52^{*}$ \\
Sep & 0.66 & $0.59^{*}$ & 0.20 & $0.31^{*}$ & 0.08 & 0.04 & 0.49 & $0.50^{*}$ \\
\hline
\end{tabular}

Note: * means statistically significant

\section{Conclusions}

Accurate datasets of time series of water bodies is crucial to quantify spatial-temporal changes of surface water, thus facilitating understanding natural variability and human interaction. This study utilized water detection method proposed by Che at el to accurately derive lakes extent on Qinghai-Tibet plateau. The change pattern of both the number and area of lakes was explored. In addition, the analysis of typical lake also compared to existing MODIS results, which show a better performance of the dataset in this study. However, this study just focused on the change of the number and area of lakes, and its response to environment change was rarely analyzed, which will be ongoing applications of water product.

\section{Acknowledgements}

This research was financially supported by Basic scientific research operating expenses of the Chinese academy of surveying and mapping (No. 20603020004096004 AR1904, 7771817) and the National Key Research and Development Program of China (No. 2017YFB0503502,
2017YFB0503601). The authors are indebted to National Aeronautics and Space Administration (http://modis.gsfc.nasa.gov), the U.S. Geological Survey server (http://glovis.usgs.gov) and the Global Land Cover Facility (http://www.landcover.org) for providing the MODIS and Landsat.

\section{References}

Baldi P., Long A.D. A Bayesian framework for the analysis of microarray expression data: regularized t-test and statistical inferences of gene changes [J]. Bioinformatics, 2001, 17(6): 509-519.

Barnett T.P., Adam J.C., Lettenmaier D.P. Potential impacts of a warming climate on water availability in snow-dominated regions [J]. Nature, 2005, 438(7066): 303-309.

Bai J., Chen X., Li J., et al. Changes of inland lake area in arid Central Asia during 1975-2007: a remote-sensing analysis [J]. Journal of Lake Sciences, 2011, (01): 80-88.

Berk A., Bernstein L.S., Robertson D.C., MODTRAN: A moderate resolution model for LOWTRAN[R]: SPECTRAL SCIENCES INC BURLINGTON MA, 1987.

Che X., Yang Y., Feng M., et al. Mapping extent dynamics of small lakes using downscaling MODIS surface reflectance[J]. Remote Sensing, 2017, 9(1): 82.

Che X., Feng M., Jiang H, et al. Detection and Analysis of Qinghai-Tibet Plateau Lake Area from 2000 to 2013 [J]. Journal of earth information science, 2015, 17(1): 99-107.

Che X., Feng M. The derivation of monthly surface water bodies over Central Asia. Remote sensing, 2018 (being be published).

Chen C., Fu W., Hu Z., et al. Changes of main lakes in central Asia in recent 30 years based on remote sensing technology [J]. Remote sensing of land resources, 2015, (01): 146-152.

Feng L., Hu C., Chen X., et al. Assessment of inundation changes of Poyang Lake using MODIS observations between 2000 and 2010 [J]. Remote Sensing of Environment, 2012, 121: 80-92.

Feyisa G.L., Meilby H., Fensholt R., et al. Automated Water Extraction Index: A new technique for surface water mapping using Landsat imagery [J]. Remote Sensing of Environment, 2014, 140: 23-35.

Hanjra M.A., Qureshi M.E. Global water crisis and future food security in an era of climate change [J]. Food Policy, 2010, 35(5): 365-377.

Klein I., Dietz A.J., Gessner U., et al. Evaluation of seasonal water body extents in Central Asia over the past 27 years derived from medium-resolution remote sensing data $[\mathrm{J}]$. International Journal of Applied Earth Observation and Geoinformation, 2014, 26: 335-349.

Lehner B., Döll P. Development and validation of a global database of lakes, reservoirs and wetland [J]. Journal of Hydrology, 2004, 296(1-4): 1-22.

Li D. Ordinary Least Square [J]. Encyclopedia of Microfluidics \& Nanofluidics, 1989: 1583-1583. 
Liu J., Wang S., Yu S., et al. Climate warming and growth of high-elevation inland lakes on the Tibetan Plateau[J]. Global and Planetary Change, 2009, 67(3-4): 209-217.

Lu A, Yao T, Wang L, et al. Changes of typical glaciers and lakes on the Qinghai-tibet plateau [J]. Journal of Glaciology and Geocryology, 2005, 27(6): 783-792.

Lu C., Ge Y., Xie G. Tibetan Plateau serves as a water tower. In Proceedings of the IEEE International Geoscience and Remote Sensing Symposium [C]. 2005: 3120-3123.

Messager M.L., Lehner B., Grill G., et al. Estimating the volume and age of water stored in global lakes using a geo-statistical approach [J]. Nature communications, 2016, 7: 13603.

Pekel J.-F., Cottam A., Gorelick N., et al. High-resolution mapping of global surface water and its long-term changes [J]. Nature, 2016, 540(7633): 418-422.

Sun F., Zhao Y., Gong P., et al. Monitoring dynamic changes of global land cover types: fluctuations of major lakes in China every 8 days during 2000-2010 [J]. Science Bulletin, 2014, 59(2): 171-189.

The national disaster monthly report. Disaster Reduction in China. 2007(08):54-63.

Wang S., Dou H,. Chinese lakes [M]. Beijing: Science Press. 1998.

Wan L., Cao W., Zhou X., et al. Changes of the water environment in the headwater area of the Yellow River and the cause for the zero-flow of the river occurring in winter [J]. Regional Geology of China, 2003.

Wu J., Ma L., JI L. Lake Surface Change of the Aral Sea and Its Environmental Effects in the Arid Region of the Central Asia [J]. Arid Land Geography, 2009, (03): 418422.

Wu S., Chang G, Li F, et al. Recent lake changes in Maduo County, source region of the Yellow River [D]. Science Press, 2008.

Yan Q., Liao J., Sheng G. Remote sensing analysis and hydrological model simulation of the variation of Ulan Ula lake in recent 40 years [J]. Remote sensing of land resources, 2014, (01): 152-157.

Zhang G., Xie H., Kang S., et al. Monitoring lake level changes on the Tibetan Plateau using ICESat altimetry data (2003-2009)[J]. Remote Sensing of Environment, 2011, 115(7): 1733-1742. 